\section{Obs Gyne Review - Journal of Obstetric and Gynecology}

\title{
A rare case of prolapse of ovarian cyst through vaginal vault
}

\author{
Rao KG. ${ }^{1 *}$, Rao G. ${ }^{2}$, Lakshminarayana K. ${ }^{3}$, Devi K. ${ }^{4}$ \\ DOI: https://doi.org/10.17511/joog.2020.i01.05
}

\footnotetext{
${ }^{1 *}$ K Gangadhara Rao, Professor, Department of Gynaecology, NRI Medical College and General Hospital, Guntur, Andhra Pradesh, India.

2 G Srinivasa Rao, Professor, Department of Urology, NRI Medical College and General Hospital, Guntur, Andhra Pradesh, India.

3 Lakshminarayana K, Professor, Department of Family Medicine, NRI Medical College and General Hospital, Guntur, Andhra Pradesh, India.

${ }^{4}$ K Prabha Devi, Professor, Department of Gynaecology, NRI Medical College and General Hospital, Guntur, Andhra Pradesh, India.
}

\begin{abstract}
Hysterectomy is the most common gynecological major surgery. It is performed for both benign and malignant conditions of the female genital tract. Common indications of hysterectomy include abnormal uterine bleeding (fibroids, adenomyosis), pelvic inflammatory disease. It can be performed via abdominal or vaginal routes depending on the pathology. In this era of minimally invasive surgery, laparoscopic hysterectomy is gaining popularity. Complications of this surgery depend on the etiology, route of hysterectomy and the technique used. Common complications of this procedure include infections, hemorrhage, thromboembolism, urinary tract, gastrointestinal injury. Vault prolapse can also occur years after performing a hysterectomy. Prolapse of fallopian tubes and omentum through the vault have been reported. However, prolapse of other abdominal and pelvic organs like bowel, ovary, and bladder through the vaginal vault is a rare entity. Prolapse of the ovarian cyst through vaginal vault has so far not been reported in the world literature. The present case report was of a very rare case of ovarian cyst prolapse through the vaginal vault in a 35-yearold woman; which was successfully treated by laparotomy and ovarian cystectomy. Her postoperative histopathology was suggestive of mucinous cystadenoma. Her post-operative period was uneventful, and she was discharged in a stable condition.
\end{abstract}

Keywords: Ovarian cyst - Prolapse, Vault, Post Hysterectomy

Corresponding Author

K Gangadhara Rao, Professor, Department of Gynaecology, NRI Medical College and General Hospital, Guntur, Andhra Pradesh, India. Email: profkgr@gmail.com

\section{How to Cite this Article}

To Browse

Rao KG, Rao GS, Lakshminarayana K, Devi KP. A rare case of prolapse of ovarian cyst through vaginal vault. Obs Gyne Review J Obstet Gynecol. $2020 ; 6(1): 28-31$.

Available From

https://obstetrics.medresearch.in/index.php/joog/art icle/view/99

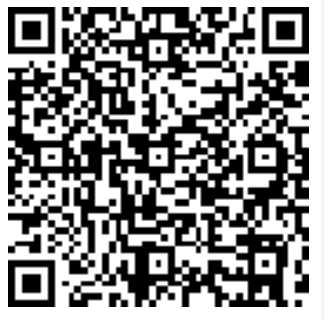




\section{Introduction}

Hysterectomy is the most common surgery performed in Gynecology. It is performed for both benign and malignant conditions. Some of the common indications for hysterectomy are fibroids, abnormal uterine bleeding, uterovaginal prolapse. Uterine fibroids account for almost one-third of the hysterectomies performed [1]. Abnormal uterine bleeding is the next common indication [1]. As with all types of surgeries, hysterectomy can sometimes cause complications.

They can be early complications like hemorrhage, infections, genitourinary and gastrointestinal injuries, anesthesia-related complications or delayed complications like vaginal vault prolapse which can occur after years of performing the surgery. Very rarely, prolapse of the bowel [2], ovary and bladder through vaginal vault can occur. Prolapse of the ovarian cyst through vaginal vault has so far not been reported in the world literature. The present case report was of a rare case of ovarian cyst prolapse through the vaginal vault ten years after hysterectomy. Ovarian cysts enlarge to large size especially ovarian tumors like serous or mucinous cystadenomas.

\section{Case Report}

Mrs. X, 35 years female married for 20 years, an agricultural laborer by occupation, presented with pain lower abdomen and low backache for the last one year. The pain was intermittent, aggravated by work, used to get relief by medication and rest. $\mathrm{H} / \mathrm{O}$ sticky watery discharge per vagina for a period of 89 months associated with itching. No dyspareunia. Hysterectomized 10 years back.

Past History: Nil Significant.

Menstrual history: Age of menarche 12 years, Menstrual History 5/30 regular, moderate flow, no dysmenorrhea.

Obstetric History: P3L3, all were normal deliveries, not tubectomised, last childbirth 15 years ago.

Past Surgical History: Hysterectomy ten years back. Right ovarian cystectomy was done three years back.

Personal / Family History: Nil significant

P/A: Both laparotomies scars were vertical and healthy.
P/S: Irregular mass of size $4 \times 3 \mathrm{~cm}$ seen prolapsing through the right side of the vault.

Yellowish gelatinous discharge present through vault gaping.

$\mathbf{P} / \mathbf{V}$ : Cystic mass of $8 \times 8 \mathrm{cms}$ palpable on the right side of the vault with restricted mobility.

P/R: Rectal mucosa free. Pelvic mass felt posteriorly $5 \times 5 \mathrm{~cm}$ firm inconsistency.

Parametrium free. The biopsy was taken from mass and sent for HPE.

U/s: $11 \times 6 \times 9.8 \mathrm{~cm}$ multicystic lesions noted in the right adnexal region - S/o Rt ovarian cyst

Other routine preoperative Investigations were done and found to be within normal limits.

Biopsy: Mucosa lined tissue bits with non-specific mixed inflammation and granulation tissue.

The lining epithelium was mucin secreting and endocervical in nature.
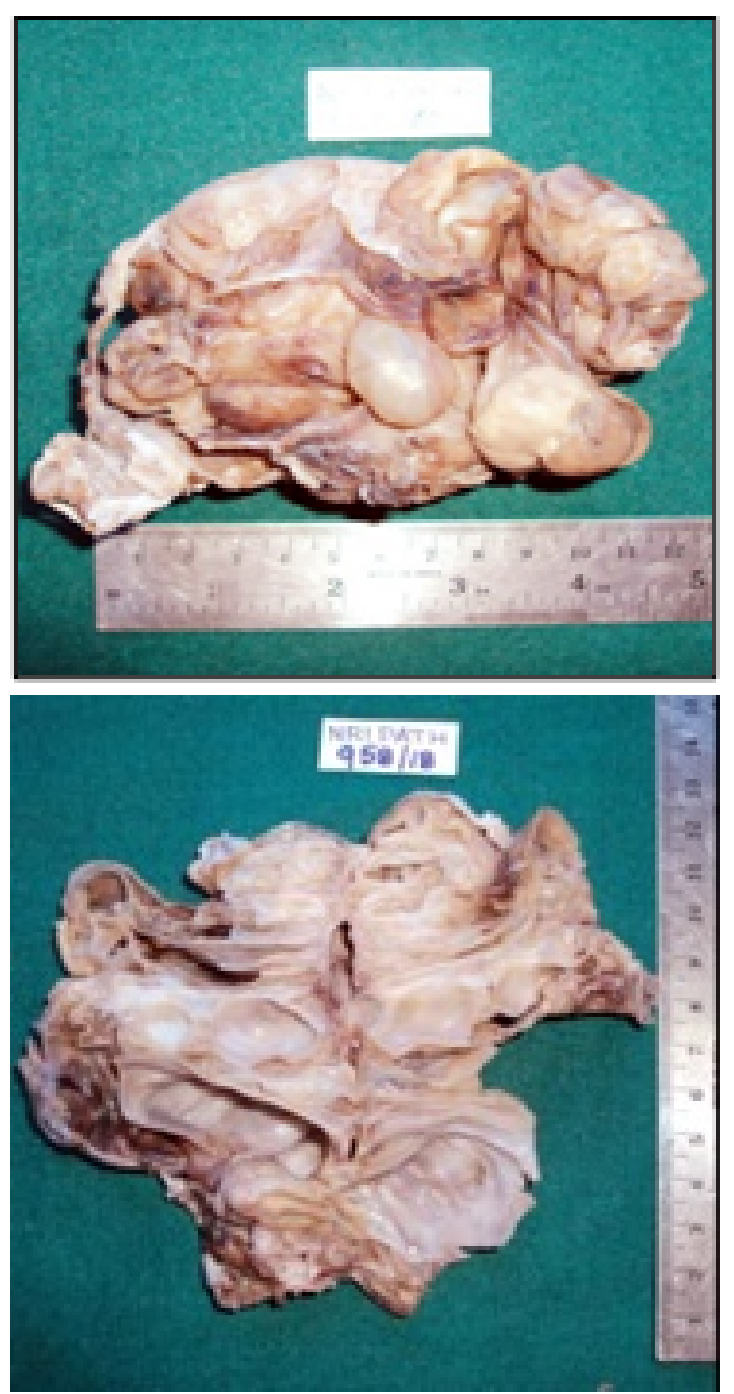

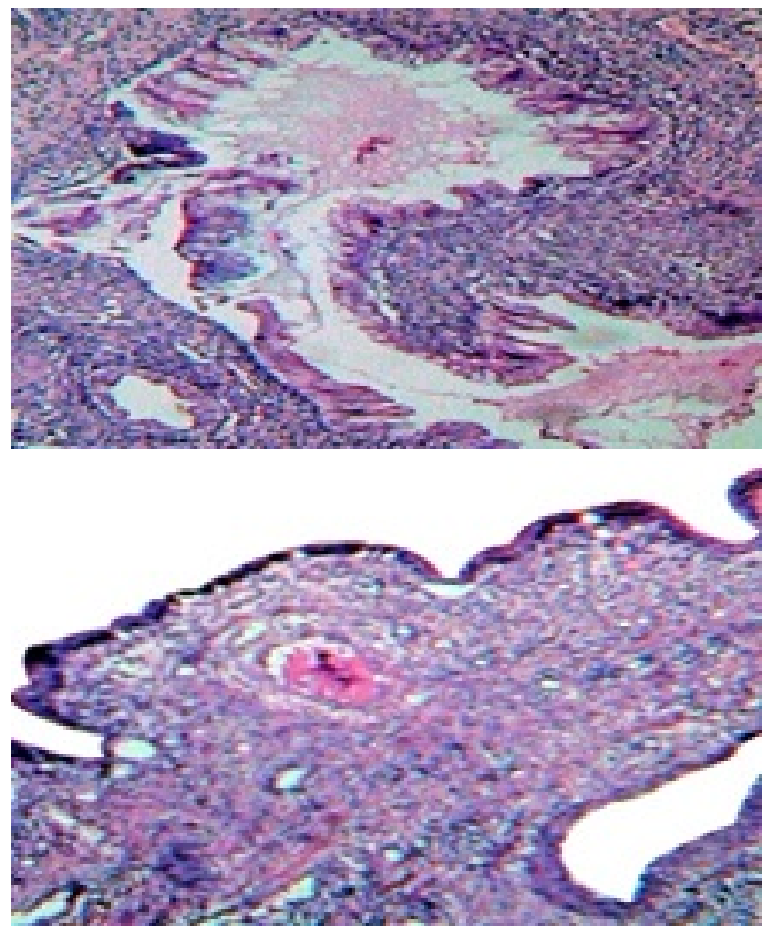

Fig-1: MRI - Contrast-enhanced showed Huge complex cystic mass - $10.9 \mathrm{~cm} \times 8.3 \mathrm{~cm} \times 9.1$ $\mathrm{cm}$ in the pelvis prolapsing through the cervical stump (Ovarian cyst prolapsing through cervical stumpor), through the vaginal vault).A cyst of size $4 \mathrm{~cm}$ also noted in the left ovary appearing to be a benign lesion.

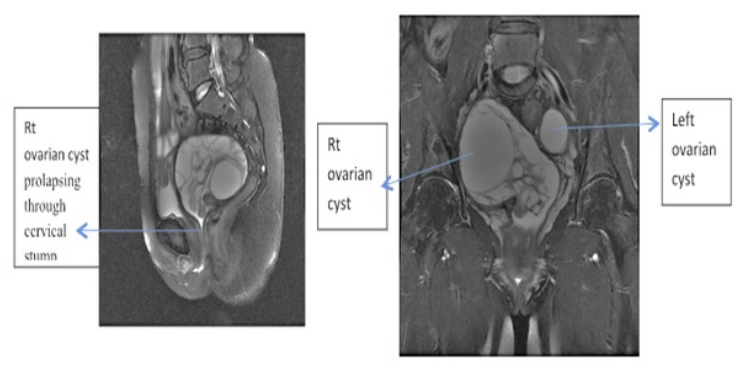

Fig-2: Laparotomy was done for the diagnosis of post-hysterectomy ovarian cyst.

Intraoperative findings: Right side retroperitoneal cystic mass of $10 \times 4 \mathrm{~cm}$ identified. Left side ovarian cyst of $5 \times 4 \mathrm{~cm}$ identified. Gaping in the vaginal vault was seen.

Operative procedure: A cystic mass of $10 \times 4 \mathrm{cms}$ in right iliac fossa retroperitoneally seen. A cystic mass of $5 \times 4 \mathrm{cms}$ seen in Left iliac fossa. Both masses were adherent anteriorly to the bladder, adhesions released carefully from the bladder. Ureter identified and separated from the mass at its lower $1 / 3 \mathrm{rd}$.
Right ovarian mass found to be extending through the vault into the vagina and adherent to the posterior vaginal wall which is separated and removed. The left ovarian cyst was removed. Gaping of the vaginal vault was sutured with vicryl.

The peritoneal cavity was washed with saline and metrogyl. Haemostasis secured. The patient withstood the procedure well. Abdomen closed in layers. One bottle of packed red cell transfused in the immediate postoperative period. Postoperative period was uneventful.
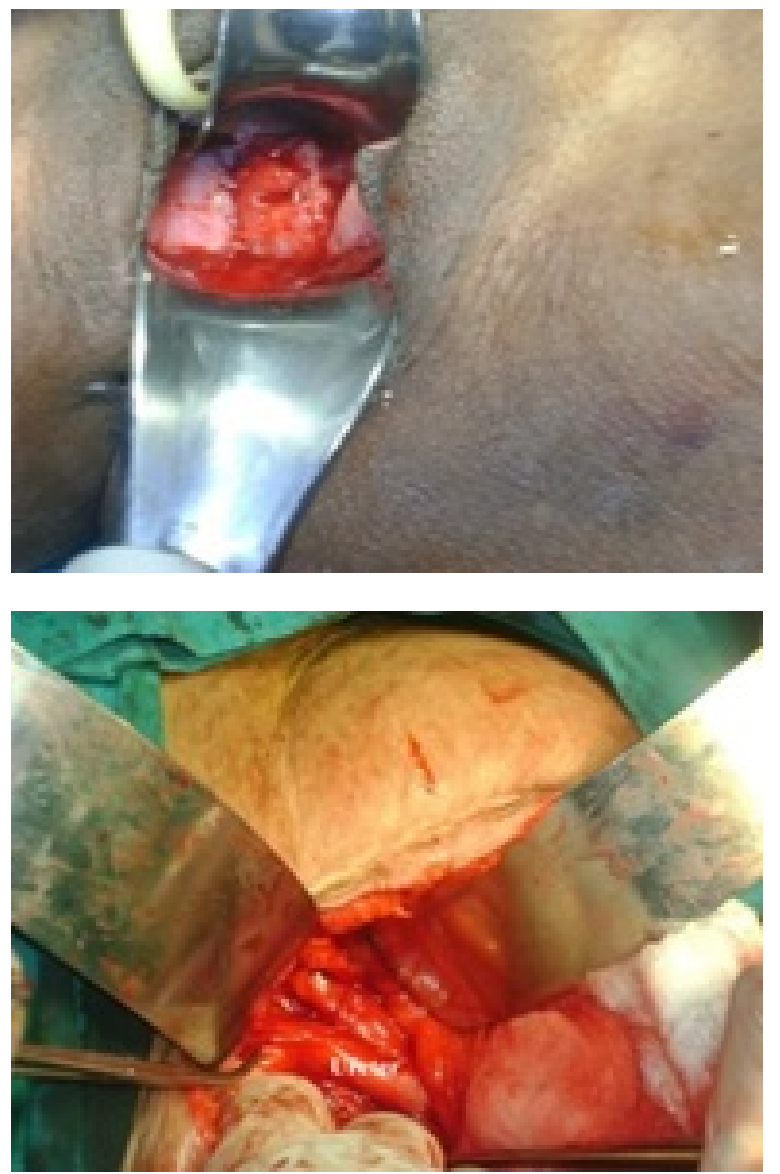

Fig-3: Nature of biopsy a) Left ovarian cyst wall, b) Right ovarian cyst

\section{Discussion}

Important points in this case: Normally ovarian neoplasm presents with mass per abdomen or pain lower abdomen and back. But in this case, ovarian neoplasm presented with vaginal discharge. So far that there is no case reported with ovarian mass prolapse through the vault. However, one case [3] reported ovarian cyst prolapsed through cervical stump following sub-total hysterectomy. 
The mass was histologically confirmed as mucinous cystadenoma postoperatively.

The incidence of Mucinous cystadenomas is $15 \%$ of all ovarian tumors $[4,5]$. These are rare before puberty [6] and after menopause (6) $80 \%$ are benign and $10 \%$ are malignant and $10 \%$ are borderline. The most frequent complications are torsion, hemorrhage, rupture, pseudo myxomatous peritonei. $10 \%$ are bilateral [7]. Recurrence is common [8]. Mucinous cystadenoma sometimes grows to the size of 10 to $30 \mathrm{~cm}$ and they may infiltrate locally to the surrounding structures.

Histologically there may be pockets of foci of malignancy and always a chance to miss. Previously there was an opinion that appendicectomy to be done when laparotomy is attempted for mucinous cystadenoma. But recent concept is that it is not necessary.

Hence, the present have not done appendicectomy. In our case, the right ovary is involved, and tumor size was about $10 \mathrm{~cm}$ and was complex cyst with multiple septae and benign in nature histologically. The tumor was densely adherent to the right ureter and there was a gap noticed in the vault. The tumor also invaded the vault and presented as mass per vagina and with gelatinous mucinous discharge.

With the help of urologist, the dense adhesions of lower $1 / 3$ rd right ureter were released. After releasing adhesions from ureter and vault, redundant vault, the ovarian mass was excised.

\section{Conclusion}

A mass per vagina in a hysterectomised patient needs to be investigated with ultrasonography and whenever necessary MRI/CT and also Laparoscopy to study the relationship of the mass with the surrounding pelvic organs (bowel, ureter) before planning for surgery.

Ideally, the ovarian tumor should be managed by a multidisciplinary team that consists of a Gynaecologist/Surgical oncologist/Urologist/Radiologist and Pathologist.

\section{Acknowledgments}

Authors sincerely thank Dr. K Prabha Devi, MD, DGO, Professor and HOD, Department of Obstetrics and Gynaecology, NRI Medical College, for her suggestions to prepare this case report.

\section{Reference}

01 . Merrill RM. Hysterectomy surveillance in the United States-1997 through 2005. Med Sci Monit. 2008;14(1)CR24-CR31.

[Crossref]

02. Rauter B. Rupture of the vaginal vault with prolapse of the small intestine (Article in German). Wien Klin Wochenschr. 1984;96(12)473-474.

[Crossref]

03. Kirwan JM, Farquharson RG, McDicken I. Prolapsed ovarian cyst through cervical stump, A rare complication of a subtotal Hysterectomy. J Obstet Gynaecol. 1998;18(5)494-495. doi:10.1080/01443619866921] [Crossref]

04. Vizza E, Galati GM, Corrado G, Atlante M, Infante $C$, Sbiroli $C$. Voluminous mucinous cystadenoma of the ovary in a 13-year-old girl. J Ped Adoles Gynecol. 2005;18(6)419-422. doi: 10.1016/j.jpag.2005.09.009 [Crossref]

05. Mittal S, Gupta N, Sharma A, Dadhwal V. Laparoscopic management of a large recurrent benign mucinous cystadenoma of the ovary. Arch Gynecol Obstet. 2008;277(4)379-380. doi:10.1007/s00404-007-0556-5

[Crossref]

06. Ozgun MT, Turkyilmaz C. A giant ovarian mucinous cystadenoma in an adolescent- a case report. Arch Med Sci. 2009;5(2)281-283. [Crossref]

07. Crum CP, Lester SC, Cotran RS. Pathology of female genital system and breast, In- Kumar $\mathrm{V}$, Abbas A, Fausto N, Mitchell R, editors. Robbins' Basic pathology. 8th ed, USASaunders/Elsevier; 2007. P 8 [Crossref]

08. Ioffe OB, Simsir A, Silverberg SG. Pathology InBerek JS, Hacker NF, editors. Practical Gynaecologic Oncology. 5th ed.

USA- Lippincott Williams and Wilkins; 2000. P 213214 [Crossref] 